\title{
How to reach a common estimate of high dietary micronutrient intakes for safe addition of vitamins and minerals to foods?
}

\author{
Niels Lyhne Andersen* and Inge Tetens \\ Department of Nutrition, National Food Institute, Technical University of Denmark, Søborg, Denmark
}

\begin{abstract}
Background: A central element in establishing maximum amount of micronutrients in fortified foods and supplements is to reach to an agreement on how to estimate high intakes of vitamins and minerals from the European diet.

Objective: To examine whether ratios between the 95th percentile and mean intakes of vitamins and minerals show similarities across different countries independent of dietary habits and survey methods and if so, to suggest a simple and pragmatic way to calculate common estimates of high micronutrient intakes from foods. Design: Intake data of selected vitamins and minerals from nine European countries were examined for adult females and males and for children aged 4-10 and 11-17 years. The ratios between the 95th percentile and mean intakes were calculated for each micronutrient, country, and age group.

Results: The ratios for each micronutrient follow a fairly regular pattern across countries and survey methods with differences between age groups.

The nutrients fall into three categories: nutrients with ratios between 1.45 and 1.58 - energy, magnesium, phosphorus, zinc, iron, vitamin $\mathrm{B}_{6}$, niacin, and folate; nutrients with ratios between 1.67 and 1.79 - calcium, selenium, vitamin E, iodine, and copper; nutrients with ratios between 2.08 and 2.32 - vitamin A, vitamin D, and retinol.

Conclusion: Sufficiently precise estimates of high micronutrient intakes across European countries can be reached by multiplying the overall average of ratios (P95/mean intakes) for each micronutrient with the corresponding mean intakes from all available dietary surveys in Europe. This approach is a simple and pragmatic way to create common European estimates of high micronutrient intakes from foods.
\end{abstract}

Keywords: 95th percentile; mean; ratio; dietary surveys

Received: 26 October 2008; Revised: 2 June 2009; Accepted: 29 June 2009; Published: 5 October 2009

$\mathrm{T}$ he EU legislation on the addition of vitamins and minerals to foods and food supplements has provided for a harmonization of the regulation on the vitamin and mineral content of fortified foods and food supplements (1-3). Several groups have addressed this topic and suggested models for safe addition of vitamins and minerals to foods (4-7). The models of Flynn et al. (4) and Rasmussen et al. (5) include all micronutrients and estimate the maximum amount of added vitamins and minerals expressed per energy unit in a kind of worst-case scenario. Contrary to Flynn, the model of Rasmussen includes children. The Finnish model tries to find a fortification concentration per energy unit that maximizes the proportion of the population for whom the intake is between the average requirement and the upper tolerable intake level (6).

A central element in the process of harmonizing regulations is to reach to an agreement on figures estimating high intakes of vitamins and minerals from the diet. Several European countries accomplish national representative dietary surveys at an individual level, which allow calculations of intake distributions of energy, macro and micronutrients and thereby estimates of high intake levels. However, for both practical and methodological reasons it is not an easy task to unite data from each survey into one common 'European' sample (4). 
Therefore a shortcut by other means is necessary in order to reach reasonable valid estimates of high dietary micronutrient intakes.

Energy intake is the most important determinant of micronutrient intake from unfortified foods at the individual level. For most vitamins and minerals, intakes are positively correlated to energy intake (8). Therefore, it is reasonable to expect some similarities in the intake distributions of micronutrients, implying similar ratios between high and mean intakes.

Based on these considerations it should be possible to suggest a simple and pragmatic way to merge dietary intake data from different countries and create common estimates of high micronutrient intakes from foods. The objective of the present study is therefore to investigate if the ratios between the 95th percentile and mean micronutrient intakes from foods show the expected similarity in dietary intake data from selected European countries.

\section{Methods}

The analysis is based on food consumption data collected in nine European countries: Denmark, Finland, Germany, Ireland, Italy, Poland, Spain, The Netherlands, and United Kingdom. The data were collected by an International Life Science Institute (ILSI) Europe Expert Group (9). The selected micronutrients are vitamin A, retinol, vitamin $\mathrm{D}$, vitamin $\mathrm{E}$, niacin, vitamin $\mathrm{B}_{6}$, folate, calcium, magnesium, iron, zinc, phosphorus, iodine, selenium, and copper. Data reflect intakes from natural sources plus mandatory fortification (practiced in Denmark, Ireland, and Poland) - other fortification and supplements are not included.

Food consumption data derive from different national representative dietary surveys (Table 1). The survey methods comprise seven-day records or diaries with estimated or weighed amounts of foods (Denmark, Ireland, Italy, and UK) and 24 (Poland) or 48-hour recall (Finland, The Netherlands, and Spain). Germany used a modified diet history and the Dutch and Spanish recalls were supplied with semiquantitative food frequency questionnaires. The data from Spain and The Netherlands have been adjusted to correct for short registration period (9).

Intake of nutrients was calculated using national food composition databases. No correction for underreporting was done. The intake data provide data from four groups: children 4-10 years, children 11-17 years, adult women, and adult men. The analytical process included Steps 2 and 3 of the following four steps for each of the selected vitamins and minerals and for each selected gender and age group:

1) Calculation of mean intakes from each of the dietary surveys (an estimate of mean European intake).
2) Calculation of the ratio between the 95th percentile and mean intake in each survey.

3) Calculation of the average of the ratios.

4) Calculation of the common estimate for high intake as the product between Steps 1 and 3 (an estimate of European 95th percentile intake).

\section{Results}

Average ratios for each country and the overall average arranged in ascending order are shown in Table 2. The results show that for each nutrient the ratio has approximately the same value from one survey to another, implying that the ratio between high and average intake of micronutrients follows a regular pattern across countries and survey methods. However, some impact of the dietary intake methodologies can be identified. The Polish ratios are systematically higher than those of the other countries due to the short registration period, which causes a wider intake distribution. The Spanish and to some extent also the Dutch ratios are lower than the others probably because of adjustment of primary data. In the present analysis it was decided not to exclude any of these results.

Overall, the ratios can be divided into three categories:

1) One category with overall ratios of the 95th percentile and mean intake between 1.48 and 1.58; this range in ratios is close to the energy ratio (1.45) and includes the nutrients: magnesium, phosphorus, zinc, iron, vitamin $\mathrm{B}_{6}$, niacin, and folate.

2) Another category has overall ratios in the range between 1.67 and 1.79 and includes the nutrients: calcium, selenium, vitamin $\mathrm{E}$, iodine, and copper.

3) A third category has overall ratios in the range of 2.07-2.32 and comprises the nutrients: vitamin $\mathrm{A}$, vitamin $\mathrm{D}$, and retinol.

In Table 3, ratios of energy and micronutrients for young and older children, and adult females and males are presented. No large differences between adults and children aged 4-10 years are seen. Ratios for the group of young children tend to be slightly lower than the ratios for adults. The intake distributions of children aged 11-17 years are wider and thus the ratios higher because of a wider range in energy requirements in this group. An exception from this tendency is the ratios of vitamin A, vitamin $\mathrm{D}$, and retinol, which are lower than other group values.

\section{Discussion}

The results of the present study show that the ratio between high and mean intake for each micronutrient is fairly stable from one survey to another. The similarity 
Table 1. National dietary surveys with information on year, methodology, survey size, and age range

\begin{tabular}{|c|c|c|c|c|c|}
\hline Country & Year & Methodology used & $n$ & $\begin{array}{l}\text { Age range } \\
\text { (years) }\end{array}$ & Reference \\
\hline Denmark & $2000-2004$ & Seven-day pre-coded record & 5,885 & 4-75 & $(10)$ \\
\hline Germany & $1997-1999$ & Modified diet history & 4,030 & $18-79$ & (II) \\
\hline Finland & 2002 & $\begin{array}{l}\text { 48-hour recall }+ \text { survey on use of fortified foods, for distribution } \\
\text { modeling: Monte Carlo simulation (fortification) and C-SIDE }\end{array}$ & 2,007 & $25-64$ & $(12)$ \\
\hline \multirow[t]{2}{*}{ Ireland } & $1997-1999$ & Seven-day estimated food diary & I,379 & 1864 & $(13)$ \\
\hline & 2003-2004 & Seven-day weighed food diary & 594 & $5-12$ & \\
\hline Italy & $1994-1996$ & Seven-day record (non-pre-coded food) & 1,978 & $0-94$ & (14) \\
\hline \multirow[t]{2}{*}{ The Netherlands } & 2003 & $\begin{array}{l}\text { Two 24-hour recall in non-consecutive days and a } \\
\text { semiquantitative food frequency questionnaire }\end{array}$ & 750 & $19-30$ & (15) \\
\hline & $1997-1998$ & $\begin{array}{l}\text { Food record on two consecutive days and a semiquantitative } \\
\text { food frequency questionnaire }\end{array}$ & 5,958 & $1-95$ & $(16)$ \\
\hline Poland & 2000 & 24-hour recall & 4,134 & $1-96$ & (17) \\
\hline \multirow[t]{4}{*}{ Spain } & $2002-2003$ & Two 24-hour recall in non-consecutive days and a & 2,160 & $10-80$ & $(18)$ \\
\hline & & semiquantitative food frequency questionnaire & 1,613 & $18-64$ & \\
\hline & $1998-2000$ & One 24 -hour recall and a semiquantitative food frequency & 3,534 & $2-24$ & \\
\hline & & questionnaire & 1,860 & $4-17$ & \\
\hline \multirow[t]{3}{*}{ United Kingdom } & 1997 & $\begin{array}{l}\text { Dietary interview; seven-day food and supplements diary and } \\
\text { seven-day weighed intake }\end{array}$ & 2,127 & $4-18$ & (19) \\
\hline & 2000-200I & & $2,25 I$ & $19-64$ & $(20)$ \\
\hline & $1994-1995$ & & 1,632 & $65+$ & (2I) \\
\hline
\end{tabular}

Table 2. Average of ratios (P95:Mean intakes) from national dietary surveys in nine European countries

\begin{tabular}{|c|c|c|c|c|c|c|c|c|c|c|}
\hline & Denmark & Finland & Germany & Ireland & Italy & Poland & Spain & The Netherlands & United Kingdom & Average \\
\hline Energy & 1.45 & 1.46 & 1.53 & 1.42 & 1.42 & 1.66 & 1.34 & 1.37 & 1.42 & $\mathrm{I} .45$ \\
\hline Magnesium & 1.50 & $\mathrm{I} .48$ & 1.52 & 1.50 & 1.48 & 1.63 & 1.28 & 1.43 & 1.51 & 1.48 \\
\hline Phosphorus & 1.55 & 1.52 & 1.57 & 1.47 & $\mathrm{I} .44$ & I.7I & 1.29 & 1.41 & 1.48 & 1.49 \\
\hline Zinc & 1.51 & $-^{\mathrm{a}}$ & 1.53 & 1.58 & 1.47 & 1.72 & 1.30 & 1.39 & 1.51 & 1.50 \\
\hline Iron & 1.51 & 1.58 & 1.52 & 1.55 & 1.52 & 1.79 & 1.30 & 1.43 & 1.62 & 1.53 \\
\hline Vitamin $B_{6}$ & 1.52 & 1.63 & 1.49 & 1.58 & 1.49 & 1.80 & 1.36 & 1.42 & 1.60 & 1.54 \\
\hline Niacin & 1.52 & 1.50 & 1.53 & $-^{\mathrm{a}}$ & 1.52 & 2.06 & 1.27 & $-^{\mathrm{a}}$ & 1.54 & 1.57 \\
\hline Folate & 1.63 & 1.62 & 1.59 & 1.58 & 1.62 & 1.72 & $\mathrm{I} .4 \mathrm{I}$ & 1.49 & 1.66 & 1.58 \\
\hline Calcium & 1.70 & 1.74 & 1.73 & 1.69 & 1.57 & 2.09 & 1.38 & 1.58 & 1.64 & 1.67 \\
\hline Selenium & 1.59 & 1.51 & $\mathrm{a}^{\mathrm{a}}$ & $-^{\mathrm{a}}$ & 1.76 & 1.91 & $-^{\mathrm{a}}$ & 1.49 & $\mathrm{a}^{\mathrm{a}}$ & 1.67 \\
\hline Vitamin E & 1.69 & 1.67 & 1.70 & $-^{\mathrm{a}}$ & 1.70 & 2.19 & 1.43 & 1.64 & 1.74 & 1.72 \\
\hline lodine & 1.63 & 1.56 & 1.63 & 2.00 & $-^{\mathrm{a}}$ & 1.88 & $-^{\mathrm{a}}$ & $-^{\mathrm{a}}$ & 1.77 & 1.76 \\
\hline Copper & 1.86 & $-^{\mathrm{a}}$ & 1.59 & $-^{\mathrm{a}}$ & 1.66 & 1.72 & $-^{\mathrm{a}}$ & 2.18 & 1.63 & 1.79 \\
\hline Vitamin A (total) & 2.05 & 2.35 & 1.90 & 2.17 & 2.58 & 2.18 & 1.39 & 2.05 & 2.11 & 2.08 \\
\hline Vitamin D & 2.32 & 2.21 & 2.34 & 2.42 & 2.20 & 2.49 & 2.02 & 1.78 & 2.12 & 2.20 \\
\hline Retinol & 2.22 & 2.84 & 2.43 & 2.34 & 3.26 & 1.97 & 1.45 & 2.37 & 2.34 & 2.32 \\
\hline
\end{tabular}

${ }^{\mathrm{a}}$ Intake is not reported.

Note: The overall average is based on ratios from all gender and age groups, i.e. normally four ratios from each country. 
Table 3. Average of ratios (P95:Mean intakes) from all counties divided into age and gender groups

\begin{tabular}{|c|c|c|c|c|c|}
\hline & $\begin{array}{l}\text { Children } \\
4-10 \text { years }\end{array}$ & $\begin{array}{l}\text { Children } \\
\text { |I-17 years }\end{array}$ & $\begin{array}{l}\text { Females } \\
\geq 18 \text { years }\end{array}$ & $\begin{aligned} & \text { Males } \\
\geq & 18 \text { years }\end{aligned}$ & Average \\
\hline Energy & $1.38(7)$ & $1.49(6)$ & $1.46(9)$ & $1.46(9)$ & 1.45 \\
\hline Magnesium & $\mathrm{I} .44$ (7) & $1.53(6)$ & 1.47 (9) & $1.48(9)$ & 1.48 \\
\hline Phosphorus & I.45 (7) & $1.54(6)$ & $1.48(9)$ & $1.48(9)$ & 1.49 \\
\hline Zinc & $1.50(6)$ & $1.53(6)$ & $1.48(8)$ & I.5I (8) & 1.50 \\
\hline Iron & I.5। (7) & $1.56(6)$ & $1.52(9)$ & $1.55(9)$ & 1.53 \\
\hline Vitamin $B_{6}$ & $\mathrm{I} .53(7)$ & $\mathrm{I} .58(6)$ & $1.52(9)$ & $\mathrm{I} .54(9)$ & 1.54 \\
\hline Niacin & $\mathrm{I} .55(5)$ & $1.66(5)$ & I.54 (7) & I.54 (7) & 1.57 \\
\hline Folate & $1.54(6)$ & $1.60(5)$ & 1.59 (9) & $1.59(9)$ & 1.58 \\
\hline Calcium & 1.59 (7) & $1.69(6)$ & $1.66(9)$ & $1.73(9)$ & 1.67 \\
\hline Selenium & $1.63(4)$ & $1.72(4)$ & $1.68(5)$ & $1.65(5)$ & 1.67 \\
\hline Vitamin E & $1.68(6)$ & $1.76(6)$ & I.72 (8) & I.74 (8) & 1.72 \\
\hline lodine & $\mathrm{I} .77(4)$ & $1.86(3)$ & $1.73(6)$ & $1.74(6)$ & 1.76 \\
\hline Copper & $1.78(5)$ & $1.86(5)$ & $1.76(6)$ & $1.77(6)$ & 1.79 \\
\hline Vitamin A (total) & $2.02(7)$ & $1.89(6)$ & $2.16(9)$ & $2.17(9)$ & 2.08 \\
\hline Vitamin D & $2.10(7)$ & $2.05(6)$ & $2.31(9)$ & $2.25(9)$ & 2.20 \\
\hline Retinol & $2.03(7)$ & $1.90(6)$ & $2.58(9)$ & $2.57(9)$ & 2.32 \\
\hline
\end{tabular}

Note: Figures in parentheses are the number of countries contributing to the average.

occurs despite differences in dietary habits across countries and despite several differences of methodological nature (type of dietary survey, food composition data base, sampling procedure, etc.). This similarity probably reflects the biological nature of eating and eating a variety of foods. Ratios differ from one micronutrient to another. We divided the ratios into three rough categories in an attempt to explain the findings. Since most nutrients are widely distributed in rather low concentrations in many foods, their ratios are close to the ratio between the 95th percentile and mean energy intake (Category 1). In Category 2, intakes still follow energy intake but the intake distribution may be influenced by a few foods, which are important nutrient sources and has a skewed intake distribution, e.g. milk, which is the major source of calcium. The third category includes highly skewed intake distributions due to only a few significant food sources of the micronutrient in question. This effect may explain why the ratios for vitamin $\mathrm{A}$, retinol, and vitamin $\mathrm{D}$ are lower among the children aged 11-17 years than the three other groups, probably reflecting that most teenagers dislike fish, liver, and carrots - foods very rich in these nutrients.

The only identifiable factors clearly affecting the ratios are the length of registration period and modification of primary data. Because of the pragmatic purpose of this study and because excluding, i.e. Polish data does not change the overall ratios much, we decided to accept all survey results.
None of the survey results were corrected for underreporting. The reason for this was the assumption that most underreporters are individuals found in the lower end of the intake distribution (i.e. below mean intake) and that the pattern of underreporting is the same in all populations. If the intakes of underreporters were increased to true levels, the intake distribution would be narrowed probably without any significant increase in levels of high intakes. This means that the mean values will increase and the ratio P95/Mean will be reduced. The final product between the overall higher mean and lower ratio will be approximately unchanged.

We are fully aware of the limitations of the applied procedure where we used aggregated micronutrient data. With access to the individual data from each country a more correct estimate of high intake could be reached. But even if the calculations are not mathematically (statistically) correct they will still create an estimate of high intake, which is sufficiently valid for the purpose of the present study. The uncertainty is hardly any larger than that of results from any of the single surveys.

One could argue that simply calculating the average of 95th percentiles would be a more simple and direct way to a common estimate of high intake. This is true and the results would probably be close to the results calculated via the ratios. Another argument against the present approach is the use of mean instead of median values. But using the ratio between 95th percentile and median did not change the final results (results not shown) and 
since it is important to find figures that will satisfy all member states in the EU, we suggest the use of mean values instead of median values. Using the present method makes it possible to include mean intake estimates from dietary surveys that are not able to describe the intake distribution. This will allow us to use data from all or at least most European countries and thus increase the acceptability of the results across all EU member states.

Flynn et al. (4) used a different approach in their model for calculating safe additions to foods. They expressed in each survey the high intakes (90-97.5th percentiles) as multiples of recommended intakes and used the mean of these multiples as a representative value. However, this method does not allow use of results from surveys giving only mean intakes.

Unfortunately the ILSI study does not provide data for all nutrients but we assume that the remaining vitamins and minerals will fit into a similar pattern. It still has to be shown based on dietary intake data whether this assumption is true, before the proposed model for calculating common European estimates for high intakes of all vitamins and mineral can be implemented in administrative practice.

\section{Conclusion}

The average ratio of the 95th percentile and the mean intakes of energy and micronutrients from foods show a remarkable similarity across countries and age groups. For each nutrient it is possible based on dietary surveys from different countries to calculate a representative European average.

The average ratio of the 95th percentile and the mean intakes is a simple and suitable measure for calculation of an estimate of high intake from an estimated average intake by the four steps described in the Methods section. It is possible to include mean intake estimates from dietary surveys, which are not able to describe the intake distribution.

\section{Acknowledgements}

The authors acknowledge the ILSI Europe Expert Group on Intake of selected nutrients from foods, from fortification, and from supplements in various European countries for giving permission to use the data collected by the group. The Expert Group comprises A. Flynn, University College of Cork, Ireland; T. Hirvonen, National Public Health Institute, Helsinki, Finland; G. B. M. Mensink, Robert Koch Institute, Berlin, Germany; M. Ocké, National Institute for Public Health \& the Environment (RIVM), Centre for Nutrition and Health, Bilthoven, The Netherlands; L. Serra-Majem, University of Barcelona, Barcelona, Spain; K. Stos and L. Szponar, National Food and Nutrition Institute, Warsaw, Poland; A. Turrini, National Institute of Research of Food and Nutrition, Rome, Italy; R. Fletcher, Kellogg, Dublin, Ireland; T.
Wildermann, International Life Science Institute (ILSI), Brussels, Belgium. I. Tetens is also member of the ILSI Expert Group.

\section{Conflict of interest and funding}

The authors declare that they have no conflict of interest and have received no funding for the present paper.

\section{References}

1. Directive 2002/46/EC of the European Parliament and of the Council of 10 June 2002 on the approximation of the laws of the Member States relating to food supplements. http://www.fsai. ie/legislation/food/eu_docs/food_supplements/Dir $\% 202002.46 \%$ 20EC.pdf [cited 5 october 2008].

2. Regulation (EC) No 1925/2006 of the European Parliament and of the council of 20 December 2006 on the addition of vitamins and minerals and of certain other substances to foods. http:// eur-lex.europa.eu/LexUriServ/site/en/oj/2006/1_404/1_404200612 30en00260038.pdf [cited 5 october 2008].

3. Health and Consumer Protection Directorate-General, European Commission (2006): Discussion paper on the setting of maximum and minimum amounts for vitamins and minerals in foodstuffs. http://ec.europa.eu/food/food/labelling/supplements/ discuss_amount_vitamins.pdf [cited 5 october 2008].

4. Flynn A, Moreiras O, Stehle P, Fletcher RJ, Müller DJG, Rolland V. Vitamins and minerals: a model for safe addition to foods. Eur J Nutr 2003; 42: 118-30.

5. Rasmussen SE, Andersen NL, Dragsted LO, Larsen JC. A safe strategy for addition of vitamins and minerals to foods. Eur $\mathrm{J}$ Nutr 2006; 45: 123-35.

6. Hirvonen T, Sinkko H, Valsta L, Hannila ML, Pietinen P. Development of a model for optimal food fortification: vitamin D among adults in Finland. Eur J Nutr 2007; 46: 264-70.

7. Kloosterman J, Fransen HP, de Stoppelaar J, Verhagen H, Rompelberg C. Safe addition of vitamins and minerals to foods: setting maximum levels for fortification in the Netherlands. Eur J Nutr 2007; 46: 220-9.

8. Willett W. Nutritional epidemiology. Monographs in epidemiology and biostatistics, vol. 15. NY: Oxford University Press; 1990.

9. Flynn A, Hirvonen T, Mensink GBM, Ocké M, Serra-Majem L, Stos K, et al. Intake of selected nutrients from foods, from fortification and from supplements in various European Countries. Food \& Nutrition Research Supplement 1, 2009. DOI: 10.3402/fnr.v53i0.2038.

10. Lyhne N, Christensen T, Groth MV, Biltoft-Jensen A, Hartkopp H, Hinsch H-J, et al. Dietary habits in Denmark 2000-2002 (in Danish). Publ \# 11. Søborg, Denmark: The Danish Institute for Food and Veterinary Research; 2000.

11. Mensink GBM, Beitz R. Food and nutrient intake in East and West Germany, eight years after the reunification - The German Nutrition Survey 1998. Eur J Clin Nutr 2005; 58: 1000-10.

12. Männistö S, Ovaskainen M-L, Valsta L, editors. The National FINDIET 2002 Study. Helsinki, FI: National Public Health Institute B3; 2003.

13. Irish Universities Nutrition Alliance. North/South Ireland Food Consumption Survey. www.iuna.net; 2001 [cited 10 october 2008].

14. Turrini A, Saba A, Perrone D, Cialfa E, D’Amicis A. Food consumption patterns in Italy: the INN-CA study 1994-96. Eur J Clin Nutr 2001; 55: 571-88. 
15. Hulshof KFAM, Ocke MC, van Rossum CTM, BuurmaRethans EJM, Brants HAM, Drijvers JJMM, et al. Resultaten van de voedselconsumptiepeiling 2003. Results of the National Food Consumption Survey 2003. RIVM report 350030002; 2004 (in Dutch)

16. Ocke MC, Hulshof KFAM, van Rossum CTM. The Dutch national food consumption survey $-2++3$. Methodological issues. Arch Public Health 2005; 63: 227-41.

17. Szponar L, Sekula W, Rychlik E, Oltarzewski M, Fugurska K. Household food consumption and anthropometric survey (in Polish). Warzawa, Poland, 2003. Prace IZZ 101.

18. Serra-Majem L, Ribas-Barba L, eds. Trends in nutritional status in Catalonia, Spain (1992-2003). Public Health Nutr 2007; 10: $1339-414$.

19. Gregory J, Lowe S, Bates C, Prentice A, Jackson L, Smithers G, et al. National diet and nutrition survey: young people aged 4-18 years. Volume 1: report of the diet and nutrition survey. London: The Stationary Office; 2000.

20. Henderson L, Irving K, Gregory J, Bates C, Prentice A, Perks J, et al. National diet and nutrition survey: adults aged 19-64 years. Volume 3: vitamin and mineral intake and urinary analytes. London: The Stationary Office; 2003.

21. Finch S, Doyle W, Lowe C, Bates C, Prentice A, Smithers G et al. National diet and nutrition survey: people aged 65 years and over. Volume 1: report of the diet and nutrition survey. London: The Stationary Office; 1998.

*Niels Lyhne Andersen

Department of Nutrition

National Food Institute

Technical University of Denmark

Mørkhøj Bygade 19

DK-2860 Søborg

Denmark

Tel: +4535887337

Fax: +4535887119

Email: nlya@food.dtu.dk 